\title{
Emergy Comparison of Typical Coastal Urban Ecosystems in China
}

\author{
Fuqiang Qin, ${ }^{1}$ Lifang Wang $\mathbb{D},{ }^{1}$ and Shifen Shao ${ }^{2}$ \\ ${ }^{1}$ School of Computer Science, Northwestern Polytechnical University, Xi'an 710029, China \\ ${ }^{2}$ School of Electrical and Control Engineering, Shaanxi University of Science and Technology, Xi'an 710021, China \\ Correspondence should be addressed to Lifang Wang; wanglf@nwpu.edu.cn
}

Received 20 May 2020; Accepted 25 June 2020; Published 28 July 2020

Guest Editor: Shubo Wang

Copyright (C) 2020 Fuqiang Qin et al. This is an open access article distributed under the Creative Commons Attribution License, which permits unrestricted use, distribution, and reproduction in any medium, provided the original work is properly cited.

With outstanding geographical location and rich natural resources, coastal cities have become concentrated and active areas of human social and economic production. Furthermore, a large number of human activities have posed a great deal of ecological environmental pressure to coastal ecological areas. The emergy analysis method is selected to construct an index system with a total of nine indicators at five levels, including emergy source structure, social subsystem, economic subsystem, environmental subsystem, and comprehensive evaluation of sustainable development. The development level of subsystems and the sustainable development ability of ecosystem in Shenzhen, Dalian, Ningbo, Qingdao, and Xiamen were evaluated. The emergy sustainable index of the five cities is $0.10,0.23,0.31,0.49$, and 0.93 , respectively. According to the evaluation results, coastal cities should comprehensively optimize the population structure, reasonably develop natural resources, make efficient use of marine resources, attach importance to the source control of pollutants, and strive to build a modern economy, so as to realize the sustainable development of coastal urban ecosystem.

\section{Introduction}

The coastal zone is located in a superior geographical location, which can connect the ocean and land, and is rich in resources. Therefore, it has become a more concentrated and active area of human socioeconomic production activities. However, a large number of human activities such as industrial development, resource exploitation, and tertiary industry development have brought great ecological environment pressure to the coastal zone, making the original sensitive ecological environment of the coastal zone more unbearable [1]. Therefore, it is of great significance to evaluate the current situation of urban ecosystem and promote its healthy, scientific, and sustainable development. Shenzhen, Dalian, Ningbo, Qingdao, and Xiamen are all coastal cities, and they are all separate cities with national social and economic development plans. As a national key development city, it has a strong development momentum in recent years [2]. Compare the social, economic, and environmental development level of the above five typical coastal zone urban ecosystem, find the existing gap, provide reference for the future construction of coastal zone cities, and provide relevant basis for ensuring the sustainable development of urban ecological economy.

A variety of methods have been applied to analysis of sustainable development capacity of ecosystem by scholars. The following are three widely used evaluation methods in recent years. First, the ecological footprint analysis method: this method is a method to measure the system's sustainable development capacity based on land area [3]. Xu et al. [4] used the ecological footprint analysis method to calculate and process the statistical data of 1999 in some provinces (regions and cities) in China and evaluated the sustainability of regional social and economic development based on the relationship between ecological footprint and ecological capacity. Second, the system dynamics theory: the theory was founded by Forrest in 1956. It can use computer simulation technology to analyze the dynamic changes of the system according to the relationship between various factors within the system [5]. In the 1970s, Jia and Xu successfully introduced system dynamics into China [6]. In 2015, Wang and Wei [7] took Dalian's eco-economic system as the 
research object and used system dynamics software modeling to predict the development status of Dalian in 2020 and carried out scenario analysis based on the prediction results and the factors that constrain Dalian's sustainable development. And third, the emergy analysis method: in the late 1980s, Ulgiati et al. [8] put forward the emergy theory for the first time. Emergy can represent the amount of solar energy directly or indirectly used in the manufacture and service of a product. In the past three decades, emergy analysis, as a tool for environmental policy and resource quality evaluation, has gradually developed in the dynamic evaluation of complex systems [9]. Emergy analysis converts energy of different types and sources according to the energy value conversion rate based on solar energy, so as to measure the size of a certain energy, which is convenient for further calculation and analysis. This theory can comprehensively measure various ecological flows, thereby establishing an emergy index system and evaluating the system from various angles, and through the most effective design, the system can simultaneously achieve the maximum ecological, economic, and social benefits. Since the 1980s, emergy analysis has been widely used in various systems such as ecology, industry, economy, and astronomy [10]. By comparing the three analysis methods, it can be seen that the emergy analysis method can comprehensively consider economic, social, natural, and other factors and, through the emergy indicators calculation, comprehensively evaluate the sustainability of the ecosystem, not only for the same system at different development times. The comparison is also convenient for comparing different systems [11].

\section{System Emergy Analysis}

2.1. Data Sources. The data in this paper are taken from the 2018 Statistical Yearbook, Public Data Open Network, and National Economic and Social Development Statistical Bulletin of Shenzhen, Dalian, Ningbo, Qingdao, and Xiamen [12-17]. The renewable environmental resources energy value of each city uses 2013 data [18].

2.2. Energy System Diagram. According to the evaluation process of the emergy analysis method proposed by Odum, the first step of this study is to draw a series of energy system language symbols according to the input and output of the system and the internal material and energy flow structure of the system to draw the energy system diagram, showing the main source of energy value in the system and the relationship between each energy value [19] (see Figure 1).

2.3. Compile Emergy Analysis Table. In the traditional energy analysis process, the energy of different sources and forms cannot be directly added or subtracted. The emergy theory proposes a completely new way of thinking. The formation of any product, resource, service, and so on requires direct or indirect application of solar energy. The concept of emergy conversion rate is derived from the theory of the ecosystem food chain, and it is also a product derived from the traditional thermodynamic principles. It can represent the quantity of solar energy contained in unit energy and convert different types of energy into solar joules, thereby effectively eliminating the energy barrier [20]. The emergy conversion rate is very closely related to the energy level of the substance. Generally, the higher the energy level, the greater the corresponding emergy conversion rate [21]. Using the energy conversion rate to calculate the energy input and output of the system, compile the emergy analysis table of the basic resources of each city [22].

\subsection{Establishment of Emergy Index System. The various} evaluation indicators in the emergy theory can help researchers better understand the specific situation of the evaluation area and distinguish the total energy value of renewable and nonrenewable energy, which maintains the stable development of the area and natural and economic investment. Through this, the series is based on emergy indicators, which can clearly analyze the sustainability, reproducibility, and efficiency of the system and evaluate the ecological technology process and the overall economic level of the region [23, 24].

According to the calculation formula of emergy indicators, the relevant data of Shenzhen, Dalian, Ningbo, Qingdao, and Xiamen collected in the early stage are classified and sorted out, and the calculation is carried out according to the corresponding emergy conversion rate and the calculation formula of each indicator, and five levels of emergy source structure, social subsystem, economic subsystem, environmental subsystem, and sustainable development comprehensive evaluation are constructed in Table 1, including nine indicator systems of emergy self-sufficiency rate (ESR), emergy yield rate (EYR), emergy usage per person (EUPP), emergy density (ED), emergy money rate (EMR), emergy input rate (EIR), environment load rate (ELR), emergy waste rate (EWR), and emergy sustainable index (ESI).

\section{Analysis and Discussion of Emergy Indicators}

3.1. Source of Emergy. The coastal zone has unique geographical advantages and abundant natural resources. In order to discuss the development and utilization of local resources, this paper uses ESR to evaluate the emergy source. ESR is the ratio of the energy value of the local resources consumed to maintain the operation of the system to the energy value of various resources obtained from the outside world in a specific area and a specific time range. The level of economic development and the implementation of the policy of opening to the outside world are different. As shown in Figure 2, Xiamen's ESR is only $37.60 \%$, which is the weakest in self-sufficiency among the five cities. It shows that Xiamen's urban life support system relies more on nonrenewable and purchased resources from the outside world. On the other hand, Ningbo's ESR is $90.26 \%$, which has a strong self-sufficiency ability, high internal resources, and development degree. Through further investigation and research, it can be found that Ningbo and Dalian, which have higher ESR, have paid attention to the development and utilization of local natural resources in recent years. The regulations on the Development, Utilization, and Protection 


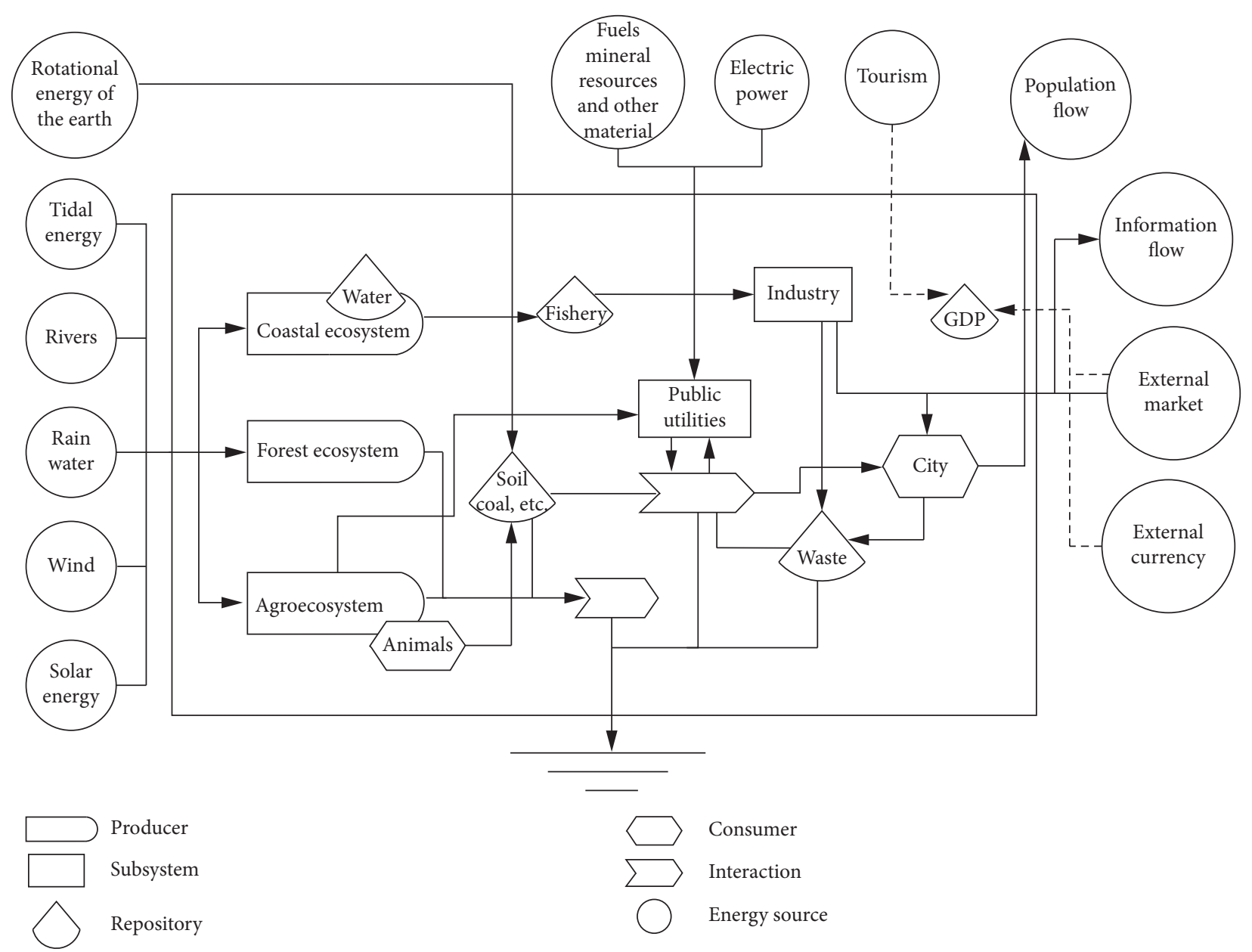

FIGURE 1: Energy flow diagram of coastal eco-economic system.

TABle 1: Calculation of emergy indicators of each city [25].

\begin{tabular}{|c|c|c|c|c|c|c|c|c|}
\hline Indicators & $\begin{array}{l}\text { Representative } \\
\text { symbol }\end{array}$ & $\begin{array}{l}\text { Calculation } \\
\text { formula }\end{array}$ & Shenzhen & Dalian & Ningbo & Qingdao & Xiamen & Indicator meanings \\
\hline $\begin{array}{l}\text { Emergy self- } \\
\text { sufficiency rate (\%) }\end{array}$ & ESR & $(\mathrm{R}+\mathrm{N}) / \mathrm{U}$ & 50.12 & 85.26 & 90.26 & 67.78 & 37.60 & $\begin{array}{l}\text { Measure system development } \\
\text { self-sufficiency }\end{array}$ \\
\hline Emergy yield rate & EYR & $\begin{array}{c}(\mathrm{R}+\mathrm{N}+\mathrm{IMP}) / \\
\mathrm{IMP}\end{array}$ & 2.00 & 6.78 & 10.27 & 3.10 & 1.60 & $\begin{array}{l}\text { Reflect the foreign trade gains } \\
\text { and losses of the eco-economic } \\
\text { system }\end{array}$ \\
\hline $\begin{array}{l}\text { Emergy usage per } \\
\text { person }\left(10^{17} \mathrm{sej} /\right. \\
\text { person })\end{array}$ & EUPP & $\mathrm{U} / \mathrm{P}$ & 2.18 & 3.26 & 5.33 & 0.79 & 1.21 & $\begin{array}{l}\text { Reflect the living standard and } \\
\text { quality of the population }\end{array}$ \\
\hline $\begin{array}{l}\text { Emergy density } \\
\left(10^{13} \mathrm{sej} / \mathrm{m}^{2}\right)\end{array}$ & $\mathrm{ED}$ & $\mathrm{U} / \mathrm{A}$ & 2.78 & 1.54 & 15.94 & 0.65 & 2.85 & $\begin{array}{c}\text { System development strength } \\
\text { and intensity }\end{array}$ \\
\hline $\begin{array}{l}\text { Emergy money } \\
\text { rate }\left(10^{12} \mathrm{sej} / \$\right)\end{array}$ & EMR & U/GNP & 8.19 & 18.66 & 21.80 & 4.49 & 7.50 & $\begin{array}{l}\text { Reflect system technological } \\
\text { progress and economic } \\
\text { modernization }\end{array}$ \\
\hline Emergy input rate & EIR & $\mathrm{IMP} /(\mathrm{R}+\mathrm{N})$ & 1.00 & 0.17 & 0.11 & 0.48 & 1.66 & $\begin{array}{l}\text { Reflect the harmonious degree } \\
\text { of system economic } \\
\text { development and resource and } \\
\text { environmental pressure }\end{array}$ \\
\hline $\begin{array}{l}\text { Environment load } \\
\text { rate }\end{array}$ & ELR & $(\mathrm{N}+\mathrm{IMP}) / \mathrm{R}$ & 20.52 & 29.21 & 33.12 & 6.29 & 1.72 & $\begin{array}{l}\text { Measure the pressure of human } \\
\text { social and economic activities } \\
\text { on resources and environment }\end{array}$ \\
\hline $\begin{array}{l}\text { Emergy waste rate } \\
\left(10^{-3}\right)\end{array}$ & EWR & $\mathrm{W} / \mathrm{R}$ & 3.18 & 6.51 & 5.62 & 3.69 & 0.18 & $\begin{array}{c}\text { Measure the pressure of waste } \\
\text { on the environment }\end{array}$ \\
\hline $\begin{array}{l}\text { Emergy } \\
\text { sustainable index }\end{array}$ & ESI & EYR/ELR & 0.10 & 0.23 & 0.31 & 0.49 & 0.93 & $\begin{array}{l}\text { Measure the sustainability of } \\
\text { the system }\end{array}$ \\
\hline
\end{tabular}

Note. R: renewable energy; N: nonrenewable energy; IMP: input energy value; $\mathrm{U}$ : total energy value usage (U = R + N + IMP); GNP: gross domestic product; P: total population at the end of the year; A: the total area. 


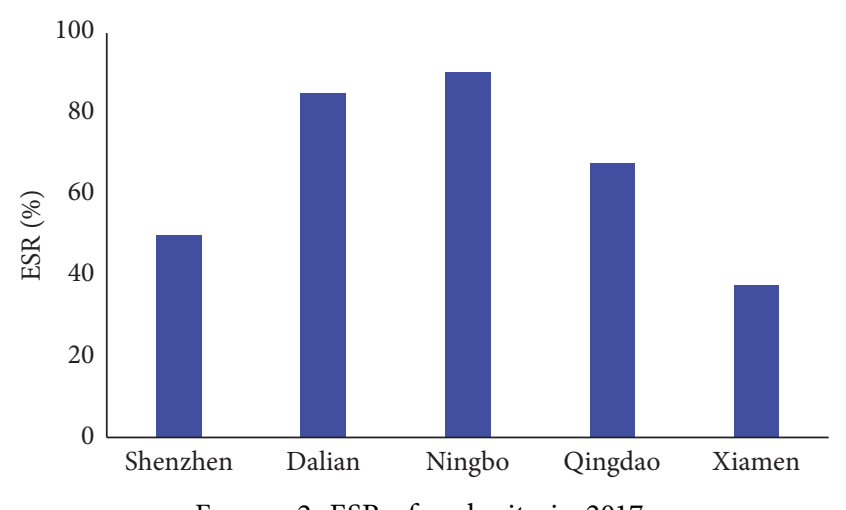

FIgURE 2: ESR of each city in 2017.

of Ningbo Climate Resources adopted by the Standing Committee of the Ningbo Municipal People's Congress in 2016 pointed out that, in addition to encouraging the installation of solar energy and other climate resource utilization systems and overall planning of wind energy projects, special tourism climate resource development should also be emphasized. Development and construction projects are integrated into natural landscapes and human landscapes. In 2013, Dalian Planning Bureau organized the preparation of Dalian coastline resources protection and development and utilization plan, which proposed the development concept of making full use of coastal resources, continuously optimizing coastline functions, adjusting measures to local conditions, and coordinating land and sea. The coastal zone is divided into ecological protection type, limited development type, and optimized development type, so as to make rational use of marine resources [26]. In addition, Dalian attaches great importance to the development and utilization of seawater chemical resources and makes the salt industry of seawater into a traditional advantageous industry. Its total direct utilization of seawater continues to be at the leading level in the country [27].

3.2. Social Subsystem. Nowadays, the improvement of people's living standards has become the foothold of social development. In order to evaluate the overall development of cities and the people's living standards, this paper selects ED and EUPP to evaluate social subsystems. ED refers to the ratio of the total amount of emergy use in a region to the area of the region. This indicator can show the intensity and level of regional development [20]. In 2017, Ningbo City's ED was $1.59 \times 10^{14} \mathrm{sej} / \mathrm{m}^{2}$, which was much larger than that of the other four cities, indicating that its social development level is the highest, and there may be two reasons (see Figure 3).

First, Ningbo's land area is small and is only 9816 square kilometers. Second, the total emergy usage of Ningbo City far exceeds that of the other four cities. EUPP refers to the amount of emergy used by each person in a particular area, which can evaluate people's living standards [28]. This indicator takes free environmental resources into consideration and can evaluate more objectively and comprehensively. In 2017, Ningbo's EUPP was $5.33 \times 10^{17} \mathrm{sej} /$ person, and Dalian's EUPP was $3.26 \times 10^{17} \mathrm{sej} /$ person. Ningbo and Dalian use more total emergy usage, and

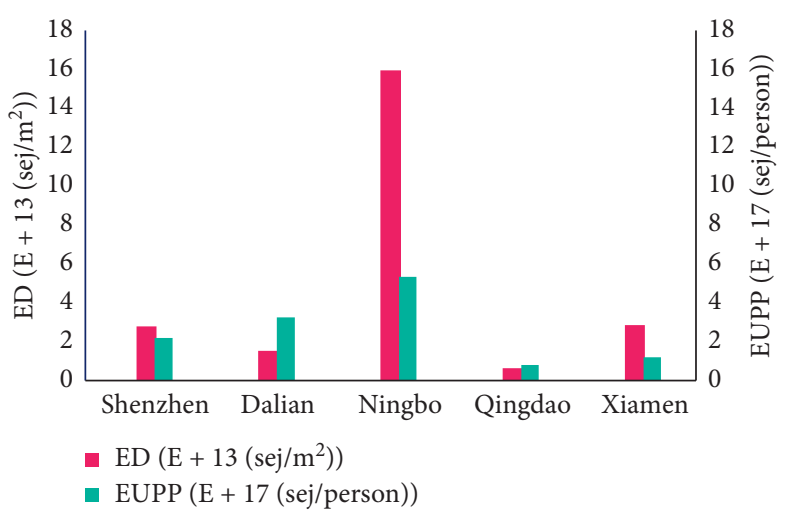

FIgURE 3: ED and EUPP in each city in 2017.

the total population is less than that in other cities, so their EUPP is more, and people's life is at a higher level. At the end of the year, the permanent population of Shenzhen was 12.5283 million, which was far more than that of the other four cities. Even though the total energy usage in Shenzhen is second only to that in Ningbo, due to the large population, Shenzhen's EUPP in five cities is still at a medium level. This is basically consistent with the urban development level reflected by ED. Therefore, the population control measures of Dalian can be used for reference to slow down the rapid population growth of each city. According to the Statistical Yearbook of the National Bureau of Statistics and the Dalian Municipal Bureau of Statistics, the fertility rate in Dalian has been consistently lower than the national level in recent years, and the fertility rate in Dalian in all other years except 2014 is less than 1\% [29]. In order to strengthen the management of the urban population's mechanical growth, the Dalian Municipal Government has perfected the establishment of relevant institutions, strengthened the examination and approval of transfer and migration population, and adopted economic measures to control the urban population's mechanical growth.

3.3. Economic Subsystem. At present, China's economy is in a transition period from high-speed development to highquality development. Therefore, starting a new journey of modernization with the construction of a modern economic system has become an urgent task in the country. In order to evaluate the current economic development status and economic modernization of each city, this paper selects EMR and EIR as indicators for evaluating economic subsystems. EMR refers to the ratio of the total emergy usage of a region in the whole year to the amount of money circulating in that year [30]. For example, some agricultural-based countries have more natural resources and do not need to spend a lot of money to purchase foreign resource products, and these countries have less circulating money in the economic field, so such developing countries have higher EMR. Conversely, a smaller EMR means that the assessed region has a higher value and high level of development. In 2017, Qingdao's EMR was $4.5 \times 10^{12} \mathrm{sej} / \$$, and Xiamen's EMR was $7.5 \times 10^{12} \mathrm{sej} / \$$, with a high degree of economic modernization (see Figure 4). 


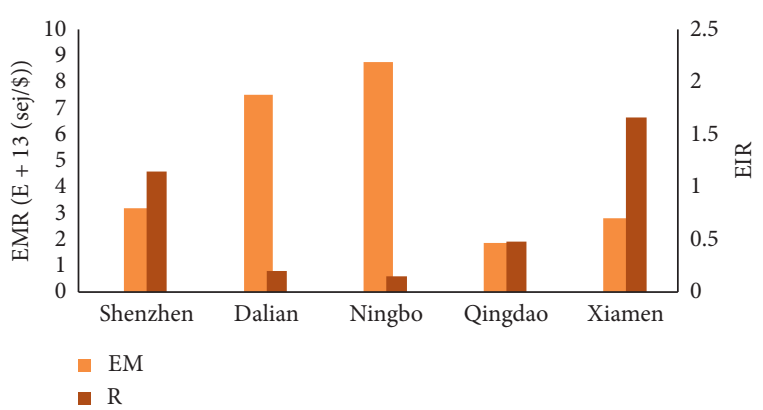

FIGURE 4: EMR and EIR of each city in 2017.

EIR can visually represent the regional economic development and reflect the current environmental load. The higher the value, the more developed the economy of the evaluation area. Conversely, when the regional development level is poor and the stability and development of the urban ecological economic system rely more on the natural environment, the value is smaller [31]. Xiamen's EIR is 1.66, and its socioeconomic development level is among the highest among the five cities. Combined with the comprehensive analysis of EMR, it can be seen that Xiamen has developed a relatively advanced economy in recent years and has a high degree of economic modernization. Therefore, we can learn from Xiamen, which has a relatively high degree of economic modernization, to adjust its own industrial structure. Xiamen is one of the first four special economic zones in China. In 2015, Xiamen City implemented the "Made in China 2025" action plan to promote the development of high-end industries. In addition, in 2017, Xiamen developed the Ziguang Science and Technology Park and built a gathering place for high-tech industries, which integrates industrial incubation, R\&D and design, and product display. The contribution rate and proportion of the tertiary industry to economic growth have exceeded those of the primary and secondary industries.

3.4. Environmental Subsystem. The nonrenewable resources consumed by human activities and the waste discharged have become the main causes of environmental degradation. Therefore, this paper selects ELR and EWR to evaluate the current status of the environmental subsystem. ELR refers to the ratio of the energy contained in nonrenewable energy and renewable energy required to maintain the operation of the system and is monitoring of the sustainability of the system [32]. It can measure the degree of regional environmental pressure. The larger the value, the greater the pressure on the regional environment. Ningbo's ELR is 33.12, which is much higher than that of Qingdao and Xiamen (see Figure 5).

It shows that the degree of environmental pressure is heavy. Human social and economic activities have a great impact on the environment, and the current situation of ecological environment is poor. EWR is the emergy ratio of waste to renewable resources, which can represent the pressure of waste on the environment. Dalian's EWR is $6.51 \times 10^{-3}$, which is much larger than that of Qingdao and

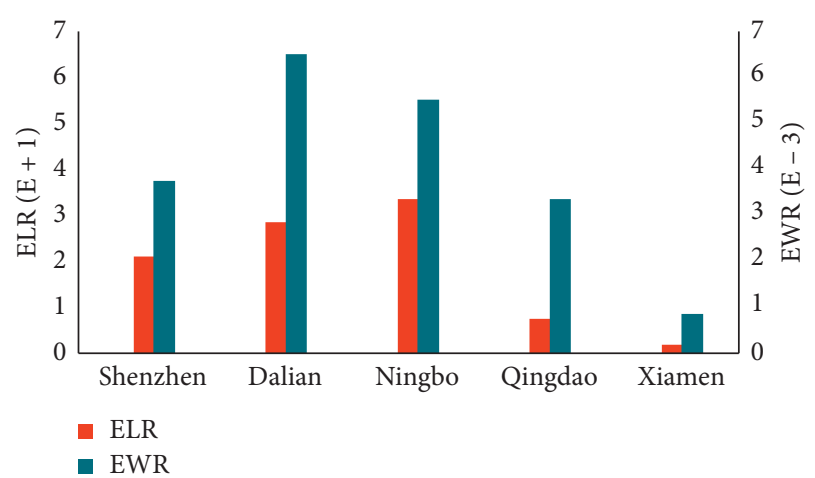

FIgURE 5: ELR and EWR of each city in 2017.

Xiamen, indicating that the waste emitted by human production activities has a greater impact on the environment. The main reason may be that, in recent years, efforts have been made to pursue rapid economic development while neglecting the maintenance of the balanced relationship between the ecological environment and the social economy, which has a negative impact on the regional environment. Therefore, we can draw on the relevant environmental policies issued by Xiamen City, which has a lower ELR, to reduce the environmental pressure on each city. For example, in November 2016, the relevant departments of Xiamen City proposed the "13th Five-Year Plan" for the energy conservation and environmental protection industry. The main task is to focus on the development of high-efficiency energy-saving industries, advanced environmental protection industries, resource recycling industries, and energy conservation and environmental protection service industries. In addition, Xiamen adheres to the overall planning of land and sea in the construction of ecological environment and issues a series of policies on land policy, which mainly focus on water body, atmosphere, soil, solid waste, and biological resources and in the field of sea area policy mainly carry out marine ecological protection and construction, marine ecosystem maintenance, marine water quality improvement, marine industry layout, marine economic agglomeration area construction, and so on [33].

3.5. System Sustainable Development. In 1998, the ESI was used for emergy analysis for the first time, which can comprehensively reflect the economic, social, and environmental benefits of the system. Its significance is to express the degree of sustainable development in numerical form, which is convenient for comparative analysis of the sustainability of different systems [34-36]. Comparing the index calculation results with Table 2, we can see that the five cities are all developed areas, and the operation of their ecoeconomic system needs to be driven by high consumption, and their sustainable development capacity is poor, which shows that, in recent years, coastal areas excessively pursue rapid economic growth and pay a large environmental cost in China. Figure 6 shows that the ESI of Shenzhen was the lowest at 0.10, and ESI of Xiamen was the highest at 0.93 in 2017. The ESI of Qingdao, Ningbo, and Dalian city decreased 
TABLE 2: ESI reference classification.

\begin{tabular}{lc}
\hline Index range & Significance of indicators \\
\hline ESI $<1$ & Developed regions, which are eco-economic systems driven by high consumption, with less sustainability \\
$1 \leq \mathrm{ESI} \leq 10$ & Developing regions, full of vitality and development potential \\
$\mathrm{ESI}>10$ & Underdeveloped areas, the system has insufficient resource development and utilization and is highly sustainable \\
\hline
\end{tabular}

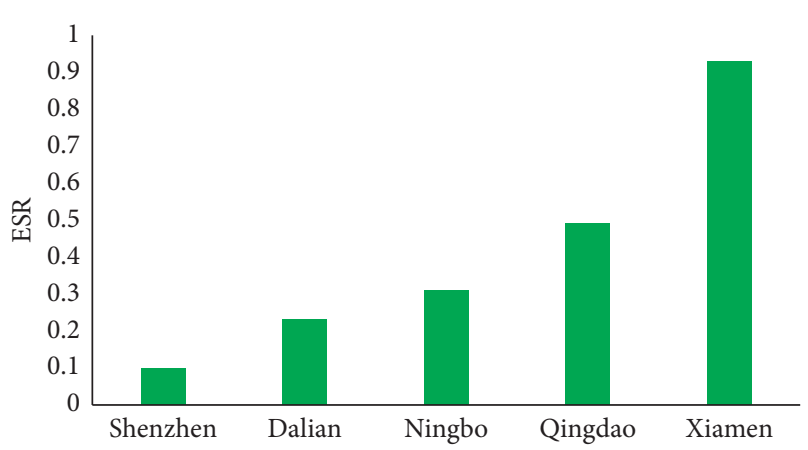

FIgURE 6: ESI of each city in 2017.

in turn. The results show that the sustainable development capacity of the five cities is weakened in the order of Xiamen, Qingdao, Ningbo, Dalian, and Shenzhen.

\section{Conclusion}

Based on the principle of emergy analysis, the resources of unreimbursed input in the environment and the output of waste are introduced into the emergy analysis framework, and the economy, environment, society, and people's living standards are integrated into the comprehensive evaluation system. The emergy index system which simultaneously reflects ecological efficiency and social and economic benefits is constructed, and the environmental load degree of coastal eco-economic system is comprehensively evaluated from three aspects: natural subsystem, social subsystem, and economic subsystem. With regard to the degree of economic development and sustainability, the following conclusions are drawn. First, the social subsystem: the population of coastal cities is increasing year by year, and the population density is highly concentrated, which puts huge pressure on the regional environment and makes the entire ecological and economic system in an oversaturated state. Second, the economic subsystem: coastal cities are more developed in economy, the import and export value and total GDP are larger, and people's living standards continue to improve, but the degree of economic modernization still needs to be improved, and economic growth relies too much on increasing capital, manpower, and material resources, inputs of production factors. Third, the environmental subsystem: coastal area waste places a greater pressure on the environment. The energy structure of each city is dominated by high-energy consumption products such as coal and oil. The transition of economic development depends on nonrenewable resources, which has caused tremendous pressure on the ecological environment for a long time. In the long run, the ecological environment will further deteriorate. And fourth, the sustainability: the production efficiency of each city's eco-economic system is at a low level; the use of subresources within the eco-economic system is unreasonable. The ESI of each city is less than 1, among which Shenzhen has the worst sustainable development ability, and its ESI is only 0.10 .

Based on the evaluation results, the following suggestions are put forward. First, adjusting the industrial layout and optimization of the population structure: the government should carry out reasonable planning and strengthen policy guidance, control population growth, moderately adjust settlement restrictions, promote the free flow of population, and further alleviate the pressure of population on the environment. Second, reasonable development and utilization of natural resources and control of nonrenewable resources and input of high-energy consumable products: we should eliminate backward production capacity, attach importance to energy-saving technology and clean production, and give full play to its resource endowment. In addition to the rational development and utilization of solar energy, we should also develop rich marine resources, such as promoting seawater source heat pumps and implementing wave power generation. Third, changing the economic growth mode and focusing on building a modern economy: the growth mode of paying too much attention to the number of export products will be transformed into a growth mode with low energy consumption, low emissions, and high efficiency. We should actively introduce advanced technology at home and abroad, realize the leapfrog development of high-tech industry, accelerate the development of the tertiary industry, and create an industrial structure centered on service economy. And fourth, increasing the development and utilization of marine resources: new technologies are used to increase the output, expand the scale of mariculture, and increase new varieties of mariculture. We should rationally develop and utilize marine resources, such as marine fishery, marine salt industry, marine shipping industry, and coastal tourism.

\section{Data Availability}

The data used to support the findings of this study are available from the corresponding author upon request.

\section{Conflicts of Interest}

The authors declare that they have no conflicts of interest.

\section{References}

[1] Y. X. Zheng and H. L. Wang, "Relationship between economy and environment of coastal zone," Journal of Tianjin University (Social Sciences), vol. 13, no. 4, pp. 308-311, 2011. 
[2] H. Xu, "Scanning the economic competitiveness of 15 viceprovincial cities in the first half of the year," China Economic Weekly, vol. 32, pp. 40-42, 2017.

[3] W. E. Rees, "Revisiting carrying capacity: area-based indicators of sustainability," Population and Environment, vol. 17, no. 3, pp. 195-215, 1996.

[4] Z. M. Xu, G. D. Cheng, and Z. Q. Zhang, "Calculation of ecological footprint and analysis of development capacity in China in 1999," Journal of Applied Ecology, vol. 14, no. 2, pp. 280-285, 2003.

[5] Y. Sun and D. M. Liang, "Application of system dynamics in environmental protection," Journal of Anhui Agricultural Science, vol. 40, no. 7, pp. 4185-4187, 2012.

[6] R. A. Jia and B. Xu, "Succession of system dynamics discipline construction-comment on frontiers and applications of system dynamics," Oriental Forum, vol. 4, pp. 125-126, 2018.

[7] G. Wang and L. S. Wei, "Simulation and analysis of dalian sustainable development model based on system dynamics," Marine Development and Management, vol. 32, no. 2, pp. 90-97, 2015.

[8] S. Ulgiati, H. T. Odum, and S. Bastianoni, "Emergy use, environmental loading and sustainability an emergy analysis of Italy," Ecological Modelling, vol. 73, no. 3-4, pp. 215-268, 1994.

[9] Y. Geng, P. Zhang, S. Ulgiati, and J. Sarkis, "Emergy analysis of an industrial park: the case of Dalian, China," Science of the Total Environment, vol. 408, no. 22, pp. 5273-5283, 2010.

[10] J. L. Hau and B. R. Bakshi, "Promise and problems of emergy analysis," Ecological Modelling, vol. 178, no. 1-2, pp. 215-225, 2004.

[11] Y. Qi and Z. H. Jiang, "Literature review on sustainable development of urban ecosystem," Cooperative Economy and Technology, vol. 589, no. 14, pp. 54-55, 2018.

[12] Qingdao Municipal Bureau of Statistics, Qingdao Statistical Yearbook, China Statistics Press, Beijing, China, 2018.

[13] Dalian Bureau of Statistics, Dalian Statistical Yearbook, China Statistics Press, Beijing, China, 2018.

[14] Ningbo Municipal Bureau of Statistics, Ningbo Statistical Yearbook, China Statistics Press, Beijing, China, 2018.

[15] Shenzhen Municipal Bureau of Statistics, Shenzhen Statistical Yearbook, China Statistics Press, Beijing, China, 2018.

[16] Xiamen Bureau of Statistics, Xiamen Statistical Yearbook, China Statistics Press, Beijing, China, 2018.

[17] Shenzhen Municipal Bureau of Statistics, "Statistical Bulletin of shenzhen's national economic and social development in 2017," 2018, http://www.stats.gov.cn/tjsj/zxfb/ 201802/t20180228_1585631.html.

[18] Z. L. Han, W. Hu, and J. Q. Zhong, "Evaluation of sustainable development of marine ecological economy in China based on emergy analysis," Acta Ecologica Sinica, vol. 37, no. 8, pp. 2563-5574, 2017.

[19] H. T. Odum, "Emergy evaluation of an OTEC electrical power system," Energy, vol. 25, no. 4, pp. 389-393, 2000.

[20] H. T. Odum, "Emergy accounting: emergy and environmental decision making," Unveiling Wealth, pp. 135-146, Springer, Berlin, Germany, 2003.

[21] B. S. Yang, "Theory and application of emergy analysis," Northeast Normal University, Changchun, China, 2006.

[22] T. Qiao, F. L. Kong, Y. Li, M. Xi, and L. Yang, "Evaluation of sustainable development of Qingdao eco-economic system based on emergy analysis," Urban Environment and Urban Ecology, vol. 28, no. 3, pp. 4-8, 2015.

[23] C. J. Jia, J. Zhang, Y. L. Zhai, and T. S. Li, "Emergy analysis of cassava-based fuel ethanol in China," in Proceedings of the
2010 The 2nd Conference on Environmental Science and Information Application Technology, pp. 486-488, Wuhan, China, July 2010.

[24] G. Zhang and W. Long, "A key review on emergy analysis and assessment of biomass resources for a sustainable future," Energy Policy, vol. 38, no. 6, pp. 2948-2955, 2010.

[25] L. H. Gao, "Emergy analysis and sustainable evaluation of ecoeconomic system in coastal areas of China," Environmental Pollution and Prevention, vol. 34, no. 8, pp. 84-86, 2012.

[26] M. S. Li and X. Cui, "Analysis on the protection and utilization of shoreline-a case study of Dalian city, Liaoning province," China Land, vol. 7, pp. 33-35, 2012.

[27] W. Z. Liu, "Scientific utilization of marine resources to develop and strengthen marine economy," Liaoning Economy, vol. 12, pp. 75-79, 2011.

[28] L. Jin, H. T. Li, and J. F. Yang, "Research on the sustainability of Afghanistan based on the emergy analysis," Journal of Resources and Ecology, vol. 9, no. 5, pp. 508-515, 2018.

[29] Y. Z. Hu, "SWOT analysis and counter measure research on the natural structure of population in Dalian," Inner Mongolia Science Technology and Economy, vol. 1, pp. 5-6, 2019.

[30] Y. T. Tian, S. L. Xue, C. H. Li, H. L. Liang, and J. S. Mao, "Sustainable development evaluation of foreign trade based on emergy analysis method in Shenzhen city, China," Sustainability, vol. 11, no. 11, p. 3035, 2019.

[31] M. T. Brown and T. R. McClanahan, "Emergy analysis perspectives of Thailand and Mekong River dam proposals," Ecological Modelling, vol. 91, no. 1-3, pp. 105-130, 1996.

[32] M. Ali, A. Marvuglia, Y. Geng et al., "Accounting emergybased sustainability of crops production in India and Pakistan over first decade of the 21st century," Journal of Cleaner Production, vol. 207, pp. 111-122, 2019.

[33] Q. L. Wang and Y. F. Li, "Integrated land-marine management for the eco-environmental development in the new era of Xiamen, China," Environmental Management in China, vol. 10, no. 6, pp. 87-106, 2018.

[34] C. H. Sui and S. F. Lan, "Emergy analysis of guangzhou and shanghai urban ecosystem," Urban Environment and Urban Ecology, vol. 19, no. 4, pp. 1-3, 2006.

[35] C. Liu, W. Cai, S. Jia et al., "Emergy-based evaluation and improvement for sustainable manufacturing systems considering resource efficiency and environment performance," Energy Conversion and Management, vol. 177, pp. 176-189, 2018.

[36] K. Lei, Z. Wang, and S. Ton, "Holistic emergy analysis of Macao," Ecological Engineering, vol. 32, no. 1, pp. 30-43, 2008. 